Viso: Cadernos de estética aplicada

Revista eletrônica de estética

ISSN 1981-4062

No 29, jul-dez/2021

$\underline{\text { http://www.revistaviso.com.br/ }}$

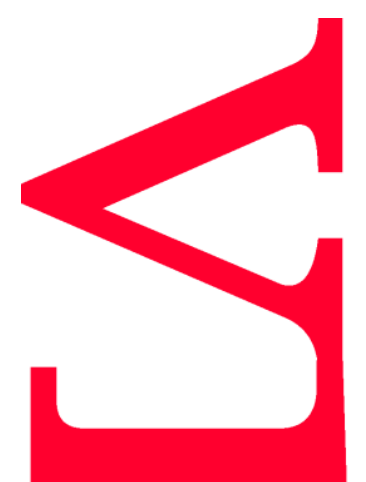

$\stackrel{0}{2}$

\title{
A pureza é um mito: Uma proposta simpoiética para a autoria nas artes \\ Debora Pazetto
}

Universidade do Estado de Santa Catarina (UDESC)

Florianópolis (SC) 


\section{RESUMO}

A pureza é um mito: Uma proposta simpoiética para a autoria nas artes

Partindo de uma problematização da autoria do Parangolé e da noção de autoria coletiva apresentada por Rodrigo Duarte nas Teses sobre a estetosfera, investigo uma proposta filosófica para a autoria artística que desvia do modelo individualista da autoria moderna ocidental, o qual considero alinhado com concepções capitalistas e puristas do processo criativo. Donna Haraway desenvolve um modelo simpoiético para descrever projetos locais, situados, que misturam técnicas, espécies, métodos, grupos, histórias e configurações socioculturais no interesse de reabilitações ou ressurgências parciais em um planeta danificado. Neste ensaio, proponho que o modelo simpoiético é mais potente para compreender práticas artísticas orientadas por criações coletivas e trocas de saberes.

Palavras-chave

autoria; Hélio Oiticica; Donna Haraway; arte contemporânea; descolonização

\section{ABSTRACT}

Purity is a Myth: A Sympoietic Proposal for Authorship in the Arts

Starting from a problematization of the authorship of the Parangole and the notion of collective authorship presented by Rodrigo Duarte in his Theses on the Aesthetosphere, I investigate a philosophical proposal for artistic authorship that deviates from the individualist model of modern western authorship, which I consider aligned with capitalist and purist conceptions of the creative process. Donna Haraway develops a sympoietic model for describing situated projects that blend techniques, species, methods, groups, histories, and sociocultural configurations in the interest of rehabilitations or partial upwellings of our damaged planet. In this essay, I propose that the sympoietic model is more relevant to understand artistic practices guided by collective creations and knowledge exchange.

Keywords

authorship; Hélio Oiticica; Donna Haraway; contemporary art; decolonization 
PAZETTO, Debora. "A pureza é um mito: Uma proposta simpoiética para a autoria nas artes". Viso: Cadernos de estética aplicada, v. 15, n² 29 (jul-dez/2021), p. 172193.

DOI: $10.22409 / 1981-4062 / \mathrm{v} 29 \mathrm{i} / 428$

Aprovado: 23.12.2021. Publicado: 30.01.2022.

(C) 2021 Debora Pazetto. Esse documento é distribuído nos termos da licença Creative Commons Atribuição-NãoComercial 4.0 Internacional (CC-BY-NC), que permite, exceto para fins comerciais, copiar e redistribuir o material em qualquer formato ou meio, bem como remixá-lo, transformá-lo ou criar a partir dele, desde que seja dado o devido crédito e indicada a licença sob a qual ele foi originalmente publicado.

Licença: http://creativecommons.org/licenses/by-nc/4.0/deed.pt_BR

Accepted: 23.12.2021. Published: 30.01.2022.

(C) 2021 Debora Pazetto. This document is distributed under the terms of a Creative Commons Attribution-NonCommercial 4.0 International license (CC-BY-NC) which allows, except for commercial purposes, to copy and redistribute the material in any medium or format and to remix, transform, and build upon the material, provided the original work is properly cited and states its license.

License: http://creativecommons.org/licenses/by-nc/4.0/ 


\section{XXI}

Este texto é o desdobramento de uma fala. Uma fala que foi assistida por 267 pessoas, até o momento em que escrevo, mas emitida em minha casa vazia, diante de 3 gatos e um monitor, no meio de um período interminável de isolamento social desigual. No meio de uma pandemia global na qual nosso país foi apontado como "pior gestão da Covid-19 no mundo". No meio de notícias que dão conta da morte de milhares de pessoas, às vezes pessoas queridas. No meio de um governo genocida, autoritário, entreguista. No meio de crimes imensuráveis contra o meio ambiente e os povos originários desse território. É no meio de tudo isso que nos sentamos sozinhas em nossas casas para debater filosofia online. Às vezes me parece heroico, às vezes patético. De todo modo, estou aqui e ressalto a origem vocal desse texto. Porque minha voz, que é meu corpo, vibra nessas linhas: um pouco apocalíptica, um pouco desconfiada de sua própria pertinência, um pouco incendiária, um pouco desanimada com a filosofia acadêmica, um pouco - e gostaria de dar vazão a essa parte - desejosa de adensar o coro de vozes que buscam atuar na construção imaginário-corporal-conceitual de formas viáveis de coexistência nesse mundo danificado.

Nesse sentido, é importante destacar - e aproveito para fazer um elogio ao formato dos encontros do GT de Estética, que retomam a origem conversadeira da filosofia em meio a tanto eremitismo acadêmico - que a fala e o texto também reverberam o Encontro do GT de 2018. Nesse último e saudoso encontro presencial, apresentei o artigo "Intersecções entre arte e tecnologia na pós-história: Uma aproximação entre Vilém Flusser e Donna Haraway", que foi debatido por Rodrigo Duarte em "Sobre pós-história e ciborgues (com um vislumbre da estetosfera)". Em seguida, no XIV Congresso Internacional de Estética, apresentei o texto "Corpo e descolonização na arte brasileira contemporânea", que era em parte uma tréplica. Assim, o que desenvolvo aqui é uma reação às "Teses sobre a 
estetosfera" de Rodrigo Duarte, mas é também o desenvolvimento de algumas ideias presentes nessa sequência de textos. ${ }^{2}$ Isso explica meu foco em dois assuntos que perpassam as XXII teses: a ênfase no corpo e, principalmente, a coletivização da autoria.

\section{VIII}

A ênfase no corpo, que aparece nas entrelinhas de todas as teses sobre a estetosfera, é explicitada na tese XVIII: "corpos humanos reunidos, paramentados, dançantes e cantantes podem perfazer, por si só, a essência de uma estetosfera". Considero esse ponto particularmente importante [em primeiro lugar porque essa descrição evoca o carnaval, e sonhar com o carnaval ajuda a manter o corpo vivo, e em segundo lugar] porque percebo a ênfase nas potências estético-políticas dos corpos como uma das principais características da arte contemporânea brasileira. Enquanto nos EUA e na Europa a desmaterialização da arte, entendida como transformação da ideia ou conceito em núcleo do processo artístico, costuma ser apontada como alicerce da arte contemporânea, no Brasil, exatamente na mesma época, as principais propostas que fundam a contemporaneidade artística colocam o corpo no núcleo do processo. É evidente que existe um refinadíssimo conceitualismo latino-americano; é evidente que existe performance e body art no norte; é evidente que a desmaterialização também envolve a ideia de ação, quase sempre esquecida, mas presente na formulação de Lucy Lippard; é evidente que não existe ideia sem matéria, o que torna "desmaterialização" um termo antipático; é evidente que não existe conceito sem corpo ou corpo sem conceito. Há diversas sutilezas nesse debate, mas aqui pretendo apenas destacar que a ênfase das principais fundadoras da arte contemporânea brasileira - como Hélio Oiticica, Lygia Clark, Lygia Pape e, bem antes [já que não precisamos obedecer aos cortes cronológicos do norte], Flávio de Carvalho - não está na depuração conceitual, mas no engajamento corporal. Por esse motivo, considero pertinente colocar a corporificação, em oposição à 
desmaterialização, no centro de uma urgente descolonização da nossa estética/crítica/teoria/história da arte.

A grande maioria da produção teórica sobre arte brasileira parte de conceitos, metodologias e epistemologias europeias ou estadunidenses. Um dos problemas disso, além do persistente colonialismo acadêmico, é que o engajamento político-corporal presente nessas experiências fundadoras costuma ser subvalorizado. O conceito de estetosfera pode ser um dispositivo interessante contra essa tendência. A ênfase no corpo é importantíssima para compreender não apenas as décadas de 1960 e 1970, mas também a produção brasileira dos últimos anos, nos quais as chamadas "pautas identitárias" começaram a conquistar espaço nas grandes instituições e editais [prefiro chamá-las de pautas descoloniais, entendendo colonização como o processo capitalista que entrelaça roubo de territórios com exploração de certos corpos via racismo, misoginia e cisheteronormatividade. ou seja, as propostas artísticas que lidam com essas feridas não são sobre identidade, mas sobre colonização e descolonização dos corpos; no entanto, talvez do ponto de vista das grandes instituições e editais, a ideia de identidade, mais próxima do individualismo burguês e mais capturável pelas políticas de representatividade do marketing empresarial, seja algo mais tolerável].

\section{VII}

Enquanto lia as teses sobre a estetosfera, eu me lembrava constantemente de algumas manifestações fascinantes da arte brasileira contemporânea, como Domingos da criação, Apocalipopótese, Mitos vadios, Orgamurbana, entre outras. Esses casos são descritos, na história da arte, como eventos colaborativos nos quais artistas compartilhavam suas propostas. O Apocalipopótese, por exemplo, foi planejado enquanto manifestação coletiva por Frederico Morais, como parte do programa "Arte no Aterro", o nome foi criado por Rogério Duarte e o evento foi constituído por propostas artísticas relativamente independentes, mas todas interligadas e transformadas pelo contexto, como as Urnas quentes de 
Antônio Manuel, o Parangolé de Hélio Oiticica e o Ovo de Lygia Pape. Não há dúvida de que o Apocalipopótese seja uma estetosfera e de que sua autoria, enquanto manifestação ou evento, seja coletiva. ${ }^{3}$ Contudo, as propostas artísticas que o integram são assinadas individualmente por artistas célebres. Por outro lado, o envolvimento do público em tudo isso, embora seja exaltado em textos críticos que falam de artista-propositor e de substituição do espectador passivo pelo participante, costuma ser descrito de forma genérica e vaga. A pergunta que me atravessa é a seguinte: será que algumas dessas propostas artísticas não poderiam ser pensadas como tendo autoria coletiva? Minha tentativa de resposta começa por uma reflexão filosófica em torno de um caso específico, o Parangolé.

\section{$\mathrm{XII}$}

Imagino que todas estão cansadas de ler que o Parangolé desloca a categoria de obra ou objeto para a categoria de acontecimento; que a ideia surgiu a partir de um envolvimento com o samba; que é um deslizamento da pintura rumo às estruturas ambientais; que é a formulação definitiva do programa da antiarte; que transforma a espectadora em participante; que a obra só se realiza sendo vestida, e não exposta como objeto inerte [embora as capas e estandartes continuem sendo expostos como objetos inertes em muitos museus]. Pois bem, não pretendo acrescentar mais um texto à já imensa fortuna crítica de Oiticica. A ideia aqui é me apropriar do Parangolé para um processo de criação filosófica, e o programa antiartístico me autoriza, ou melhor, me incentiva a isso. A ideia aqui é vestir o Parangolé para fazer girar a noção ocidental moderna de autoria nas artes visuais. Afinal, se ele provoca rupturas em tantos e tão respeitados conceitos - obra, arte, espaço, público, objeto, exposição, ambiente - por que não deslocar essa turbulência para o conceito de autoria? Para começar a dança, algumas frases do próprio Hélio em Anotações sobre o Parangolé. ${ }^{5}$

"É aí a obra muito mais 'obra-ação' do que a antiga actionpainting, puramente plasmação visual da ação e não a ação 
mesma transformada em elemento da obra" [a perspicácia dessa crítica só não é melhor do que a alfinetada: antiga]: ou seja, a ação de vestir e dançar faz parte da obra, não é algo anterior como na action painting e, principalmente, não é algo posterior a ela, não é um acréscimo.

“O que se convencionou chamar de 'interpretação' sofre uma transformação nos nossos dias [...] Nat King Cole, p.e., cria uma 'estrutura expressiva vocal', independente da qualidade das músicas que interprete há uma criação sua, não mais como simples 'intérprete"': há aqui uma analogia implícita entre o cantor e quem veste o Parangolé, para pontuar que em ambos os casos não se trata de um simples intérprete, mas de um artista criador e expressivo.

“Antiarte - compreensão e razão de ser o artista não mais como um criador para a contemplação, mas como um motivador para a criação - a criação como tal se completa pela participação dinâmica do 'espectador', agora considerado 'participador'": o artista se torna um motivador e o processo de criação desliza para a ação de vestir e dançar. Ora, a noção de criação é o alicerce do conceito ocidental moderno de autoria.

"A antiarte é a verdadeira ligação definitiva entre manifestação criativa e coletividade": essa frase é quase uma autorização para pensar o Parangolé, "a antiarte por excelência”, enquanto processo de criação coletiva, que deveria, portanto, ser assinado coletivamente [é claro que o próprio Hélio, que também tinha um lado bicha louca vaidosa, e imerso como estava no universo institucionalizado da arte, não assume essa consequência radical, ainda que ofereça o suporte teórico pra ela].

Note-se que estou sugerindo algo um pouco mais extremo do que a já tradicional ideia de artista-propositor. Não estou repetindo que o Parangolé de Hélio Oiticica é uma obra aberta, uma proposição que só se completa com a interação do público. Estou afirmando que o Parangolé não é apenas do Hélio e que seria pertinente modificar o modo de descrever sua autoria. Essa posição um pouca mais desafiadora deve-se ao fato de que 
estou pensando nas condições específicas de elaboração do Parangolé.

É bastante evidente a semelhança entre as capas e as fantasias das escolas de samba - que surgiram nos territórios populares do Rio de Janeiro no começo do século XX, sendo a Mangueira uma das primeiras -, não apenas esteticamente, mas também na ideia de que elas só se realizam quando vestidas e dançadas. 0 termo parangolé é uma gíria do morro. Hélio relatou em uma entrevista que capturou o termo quando o viu em uma construção, feita por uma pessoa em situação de rua, que era composta por quatro estacas de madeira e paredes feitas de barbante, com um pedaço de aninhagem no qual estava escrito "aqui é o parangolé". 6 Esse relato é revelador, mas quero enfatizar algo mais promíscuo do que a conhecida inspiração para palavras, frases, temas, funções, plantas, materiais, estéticas e estruturas arquitetônicas que aparecem nos Penetráveis, Ninhos, Bólides e Parangolés. Quero enfatizar a imersão criativa, ético-estético-cognitiva, na vida de uma comunidade enquanto processo que resulta na elaboração do Parangolé.

O poeta Waly Salomão, grande amigo, interlocutor e parceiro de experimentação de Oiticica, relata que o artista, rebatizado Russo por ser branco e de fora,

vagava no morro o ano inteiro, conhecia as quebradas como a palma de sua mão. Barracos, biroscas e bocas. Incorporando o modo sinuoso e abrupto, barra-pesada e festa [...] Entretecendo amizades e laços. Então ali era realizada uma atitude inaugural de imersão. Comparável à mudança de casca de uma árvore ou à mudança de pele de uma cascavel. ${ }^{7}$

Waly também conta que Hélio Ihe revelou, certa vez, que "sem essa imersão na vida densa e comunitária do morro e do samba teria sido impossível entender o alcance e desdobramento do 'corpo coletivo"'. 8 
Hélio fez aulas de samba com Miro, tornou-se passista da ala "Vê se entende", tinha um trio com Nildo e Santa Tereza, sabia até fazer o Parafuso e outros passos acrobáticos, foi, por fim, enterrado enrolado na bandeira da escola de samba sob o toque do surdo verde e rosa tocado por Ubiratan, filho do compositor Pandeirinho. Foi junto a essas pessoas reais, de carne, osso e ginga, que o Parangolé foi criado, vestido e sambado. Foi no corpo dessas pessoas que ele foi inaugurado para o mundo da arte institucionalizada, em 1965, no MAM. Foi também no corpo dessas pessoas que ele foi barrado - e este episódio também não pode ser separado do Parangolé. Trabalhos de arte não são objetos, são histórias. É por causa dessa história [e não simplesmente porque a obra se completa com a participação do público, estética relacional etc. etc. etc.] que estou sugerindo que a autoria do Parangolé deveria ser assinada da seguinte forma: Hélio Oiticica e Estação Primeira de Mangueira. Ou, melhor ainda: Hélio Oiticica, Mosquito, Miro, Nildo, Jerônimo, Tineca, Robertinho, Santa Tereza, Paulo Ramos, Vera Lúcia, Carlinhos Pandeiro de Ouro, Pedralto da Lacraia, Canhão, Lilico e Nininha Xoxoba.

\section{XIII}

Não é minha intenção diminuir a importância de Oiticica na elaboração do Parangolé, pois coautoria não diminui a autoria de ninguém. Também não estou desvalorizando a trajetória do artista, iniciada em 1959 com a saída do quadro em direção ao ambiente e à libertação da cor, com os Monocromáticos, rumo a um "programa in progress", como observa Celso Favaretto,

vendo em retrospecto a sequência de suas proposições, que a conquista desse estado disparou o processo de abertura estrutural, já indiciado em Bilaterais, Relevos espaciais, Bólides, Núcleos e Penetráveis, configurando um lúcido, rigoroso e coerente trabalho de diluição estrutural voltado à transmutação da arte. $^{9}$

De fato, Oiticica apresenta um programa ambiental bem estruturado, uma "hierarquia de ordens" em que "o conjunto 
perceptivo sensorial domina"10, como explica Mário Pedrosa. Também não estou reduzindo a importância de sua formação artística em meio a um tipo de experimentalismo que "tem origem em fatos artísticos da experiência neoconcreta"11, como afirma Luciano Figueiredo. A meu ver, todo esse discurso crítico consolidado é compatível com uma reivindicação de coautoria do Parangolé.

Por outro lado, considero problemático que a grande maioria dos textos sobre Oiticica enfatize certa linearidade em sua trajetória - Bilaterais > Relevos > Núcleos > Bólides > Parangolés -, bem como a importante influência de Mondrian, Klee, Cage e Malevich, ao passo que a Mangueira aparece como inspiração, contexto, e por vezes como uma curiosidade exótica. Essa assimetria precisa ser rebatida, é o mínimo. Não tenho dúvidas de que se a Mangueira fosse um artista europeu, e não uma comunidade negra periférica, a ênfase geral estaria na ruptura massiva que sua cultura estetosférica provocou, e não na continuidade do "projeto oiticiquiano".

\section{XIX}

A ideia de que o Parangolé deveria ser assinado coletivamente pode parecer exagerada ou sem sentido diante das práticas reais do mundo da arte. Contudo, com a recente abertura desse contexto para grupos que estiveram sistematicamente excluídos dele, talvez essas práticas estejam mudando. Um exemplo: na exposição Véxoa: nós sabemos, o artista Wapichana Gustavo Caboco assina junto com a cacique Guarani-Mbya Juliana Kerexu, o cacique Xetá Dival da Silva, a cientista social Lucilene Wapichana, o escultor e cantor GuaraniMbya Ricardo Wera e a pesquisadora Kaingang Camila dos Santos da Silva uma série intitulada Onde está a arte indígena no Paraná? A série apresenta um conjunto de objetos confeccionados por indígenas que usualmente não são considerados arte, mas artesanato ou "esculturinhas" (bicho ra'anga). Gustavo conta que percebeu que havia alguns bichos ra'anga que extrapolavam o território nacional, porque pessoas não indígenas vão até as aldeias "pedir que o 'parentinho' faça 
uma girafa, uma orca ou uma pulseira do Flamengo". ${ }^{12} \mathrm{O}$ artista reflete que indígenas são constantemente obrigados a se adequar, se embranquecer, portanto, trabalha com o raciocínio inverso, "a ideia de tornar indígena", e arremata: "a girafa se transmuta em guarani-mbya-wapichana quando eu me apresento em conjunto com a Juliana, na nossa arte". ${ }^{13}$

Essa prática de assumir criações que resultam de trocas de saberes como coletivas é muito diferente do raciocínio branco extrativista que sempre tomou "a arte indígena como inspiração ou como referência para a arte dos não indígenas" ${ }^{14}$, como aponta a curadora Naine Terena. Não por acaso, afinal, "a perspectiva artística indígena emerge justamente de outros mundos, que muito podem contribuir para uma sociedade com pensamento mais coletivo". ${ }^{15}$ Talvez esteja aí a chave da diferença entre o tokenismo cultural que temos visto em muitas instituições e uma real abertura cultural: não basta incluir pessoas historicamente marginalizadas para cumprir uma agenda politicamente correta, é preciso haver abertura para que elas possam colocar em xeque os conceitos e práticas hegemônicas.

Não acredito que Oiticica seja um artista extrativista. Waly: "o Hélio quando foi para a Mangueira vivenciou a barra-pesada num processo de ruptura e recusa do mundo burguês que o formou e rodeava. Não foi um favela tour. Foi um aprendizado gozozo e doloroso"16; e ainda: "Hélio escolheu a via da superação do etnocentrismo". ${ }^{17}$ Portanto, a ideia de que o Parangolé deveria ser assinado coletivamente não me parece exagerada ou sem sentido diante da possibilidade de abertura das práticas reais do mundo da arte.

Com relação às obras de arte, as culturas ocidentais se comportam de modo diferente das culturas indígenas. Os "sacrifícios" que as culturas ocidentais fazem consistem em manter seus trabalhos artísticos nos melhores espaços, projetados pelos melhores arquitetos, com seguros de proteção, guardas 
para vigiá-los, restauradores para conserválos, especialistas para montá-los e exibi-los, e pessoas da mais alta e educada classe social para "observá-los". As culturas indígenas mantêm as obras de arte em locais honrados e sagrados. Oferecem a elas sacrifícios de sangue (cabra ou galinha), libações de vinho. Banham, alimentam e vestem elas. As obras são tratadas não apenas como objetos, mas também como pessoas. 0 "observador" é um participante do ritual, e não é um membro das classes privilegiadas. ${ }^{18}$

IXI

A grande maioria das concepções filosóficas ocidentais sobre a arte permanece intimamente ligada à identidade autoral de um artista criador, isto é, um indivíduo capaz de expressar seus pensamentos e sentimentos por meio da obra. Essa mística também está presente na "equivocada concepção compartilhada com o senso comum do que seria a arte: a ingênua ideia de que arte é a expressão individual de uma experiência emocional, a tradução da vida pessoal em termos visuais". ${ }^{19}$ Essa perspectiva deixa ausentes ou em segundo plano as estruturas sociais, históricas, institucionais, familiares, religiosas, educacionais e, sobretudo, de classe, raça e gênero, que determinam o que chega a ser percebido como arte. Ela suscita, portanto, uma série de exclusões e apagamentos. 0 mais curioso é que, embora esteja bastante entranhada na cultura ocidental hegemônica, trata-se de uma concepção recente: a importância da autoria na arte começou a se delinear no Renascimento e se consolidou teoricamente apenas no século XVIII, com o conceito de gênio e, posteriormente, com a teoria expressiva da arte. ${ }^{20}$

Antes disso, nos ateliês medievais e nas artes populares predominavam práticas coletivas e anônimas, que aos poucos passaram a ser malvistas, "como se apenas na solidão a genialidade e a originalidade do pensamento pudessem emergir em toda sua força e intensidade. Em suma, só o indivíduo, tomado em sua riqueza interior, é capaz de produzir grandes obras de forma autoral". ${ }^{21}$ Certamente, não é uma coincidência 
que a gênese da arte concebida como atividade individual, solitária, cuja fonte está no gênio singular do indivíduo, coincida cronologicamente com a gênese do capitalismo. Como mostra amplamente Federici, o capitalismo surge em oposição a modelos medievais de vida comunal. ${ }^{22}$ Tomando as palavras de forma bem literal: o oposto do comunal [comunismo] é o individual [individualismo], que emerge com a substituição dos serviços feudais coletivos por relações individuais de exploração monetária [capitalismo]. Ou seja, a origem e manutenção do capitalismo dependem do combate a práticas comunais e da formação de subjetividades individualistas. É nesse sentido que considero o conceito moderno ocidental de autor/artista/gênio como um deslizamento do individualismo burguês para o campo das artes.

Uma das consequências do processo de afirmação da autoria individual é a desvalorização de experiências criativas baseadas em trabalhos coletivos, e "isso explica, em parte, o descaso em relação às tradicionais formas de produção e reprodução da cultura popular, geralmente coletiva, aberta e de natureza eminentemente performática". ${ }^{23}$ Quando estão imersos em uma sociedade capitalista, que protege os criadores individuais com direitos autorais e leis de proteção à propriedade intelectual, a cultura popular e os saberes tradicionais ficam desamparados, isto é, sujeitos à exploração/apropriação que os transforma em produtos assimiláveis pelo mercado. ${ }^{24}$ Incluindo o mercado artístico.

\section{XIXI}

[é claro que ninguém mais fala em gênio hoje em dia [mas pensa], porque isso é muito romântico e totalmente fora de moda. mas, como tudo no capitalismo, o conceito foi repaginado de acordo com as necessidades da época. no mercado de arte atual, o nome do artista desempenha um papel muito semelhante ao que a marca ou a grife desempenham no mercado da moda. o modelo ocidental individualista $\mathrm{e}$ glamourizado de autoria é um dos principais mecanismos nos processos contemporâneos de mercantilização da arte]. 
[será que ficou flagrante que meu interesse central não é defender a autoria coletiva do Parangolé? que isso é uma fabulação, um experimento mental no estilo Wittgenstein, quase uma provocação? que meu interesse central é investigar um modelo filosófico para a autoria artística que se desvie do modelo tradicional artista-gênio-individual?]

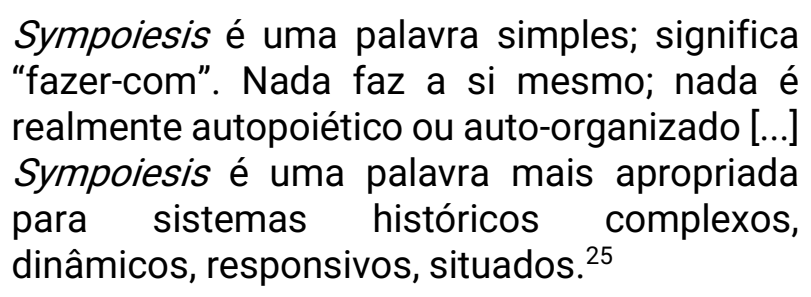

Em seu livro mais recente, Staying with the Trouble, Haraway defende uma perspectiva filosófica não individualista e não antropocêntrica a partir de um jogo com o significante SF: String Figures, Science Fact, Science Fiction, Speculative Fabulation, Speculative Feminism, So Far. O rompimento intencional das fronteiras entre indivíduos [Waly: agora, entre o meu ser e o ser alheio, a linha de fronteira se rompeu], fatos científicos, fatos sociais, ficção e fabulação torna-se ainda mais evidente do que no Manifesto Ciborgue. Todo o livro - que a autora afirma ser particularmente impaciente com duas respostas comuns às catástrofes geradas pelo capitalismo: a fé cômica de que a tecnologia de algum modo virá salvar seus filhos travessos, porém muito espertos, e o futurismo apocalíptico antitecnológico que já entregou o jogo como vencido - se articula em torno de fusões entre arte, ciência e política. "Estou comprometida com mundanizações artístico-científicas como práticas simpoiéticas para viver em um planeta danificado". ${ }^{26}$ Práticas simpoiéticas: projetos locais, situados, que misturam técnicas, espécies, métodos, grupos, histórias e configurações socioculturais no interesse de reabilitações ou ressurgências parciais.

Inspirado na teoria sobre a origem simbiótica de células, tecidos, órgãos e espécies formulada pela bióloga Lynn Margulis, o termo sympoiesis foi proposto em 1998 pela ambientalista Beth 
Dempster para descrever sistemas de produção coletiva que não têm limites espaciais ou temporais definidos, nos quais a informação e o controle são distribuídos entre componentes, e que têm potencial para mudanças surpreendentes. É um termo que surge, portanto, em contraste com a ideia de atividades ou indivíduos entendidos como unidades autônomas, puras, com limites temporais e espaciais definidos, que tendem ao controle centralizado. ${ }^{27}$ Haraway adota o termo de forma ampla, como modelo para compreender o motor da vida e da morte neste planeta: a atração irresistível entre criaturas que se envolvem, se interpenetram, se devoram, se digerem e se movimentam em torno umas das outras.

O termo simbiose costuma ser utilizado na biologia clássica que descreve os seres como unidades individuais ligadas por meio de relações que são sempre pensadas em termos de competição ou cooperação - como sinônimo de benefício mútuo. No entanto, esse uso raso oblitera o emaranhado heterogêneo de processos dinâmicos envolvidos no manejo das vantagens e desvantagens dos simbiontes. Em outras palavras: um jogo de soma zero baseado em indivíduos que competem pela sobrevivência é apenas uma caricatura purista das fusões sensuais, químicas, semiossomáticas que possibilitam a vida e a morte em nosso mundo.

No modelo simpoiético, os arranjos conhecidos como células, organismos e ecossistemas resultam de relações: "criaturas não precedem seus relacionamentos; elas se fazem mutuamente por meio de envolvimento semiótico-material, a partir de seres que provém de emaranhados anteriores" ${ }^{28}$ Assim, a atenção se dirige para as relações e não para os indivíduos, ou melhor, simbiontes, ou melhor, holoentes [ou melhor: participantes?].

Em suma: estou sugerindo que o modelo individualista da autoria moderna ocidental se alinha com uma concepção purista do processo criativo. E que o modelo simpoiético, portanto, é mais potente para compreender práticas artísticas orientadas por criações coletivas e trocas de saberes. Em outras palavras: a pureza é um mito. 
Importa quais histórias contamos para contar outras histórias; importa quais nós amarram nós, quais pensamentos pensam pensamentos, quais descrições descrevem descrições, quais laços enlaçam laços. Importa quais histórias fazem mundos e quais mundos fazem histórias. ${ }^{29}$

IV

Se o Parangolé fosse compreendido no modelo simpoiético, será que os passistas da Mangueira teriam sido barrados na Opinião 65? O MAM expulsaria os artistas de sua própria exposição? Oiticica estava na programação oficial, mas não da forma como apareceu, em meio a um cortejo de passistas da Mangueira, dançando, batucando e trazendo as capas em seus corpos negros e periféricos. Impedidos de entrar no cubo branco e chique. "Hélio, bravo no revertério, disparava seu fornido arsenal de palavrões: - Merda! Otários! Racismo! Crioulo não entra nessa porra!". ${ }^{30}$

É bastante conhecido esse episódio vergonhoso de 1965, mas é menos conhecida sua repetição trágico-farsesca em 1994. Na $22^{a}$ Bienal de São Paulo, ao ver que o Parangolé estava confinado em um cubículo perto da saída de serviço do Pavilhão do Ibirapuera, Luciano Figueiredo rebeldemente convidou os passistas da Mangueira, vindos de ônibus do Rio de Janeiro, a desfilar por toda a exposição vestindo as capas. Ninguém descreve o ocorrido melhor do que Waly Salomão:

0 curador Wim Beeren, um tipo de holandês que possui inscrito em seu código genético a noção de apartheid, de dedo em riste, berrava assustado com o crioléu gingando sob o comando do veterano parangolista Paulo Ramos:

- Get out! Get out! Get out!

Vermelho, possesso, a cabeça aterrorizada por todos os clichês dos selvagens canibais africanos de Hollywood, o batavo Wim Beeren usava a voz como chicote nos lombos dos zulus, apoplético na direção da assanhada e 
pirracenta Nenete (Lisonete Freitas de

Almeida):

- Get out! Get out! Get out!

Temor e tremor, suor frio, olhos esbugalhados, Wim Beeren açoitava Ronaldo "Negro do Burrão"

- Get out! Get out! Get out!

Wim Beeren praticou essa ressurgência colonialista dos bôeres na pauliceia desvairada, uma agressão do pânico racista sobre brasileiros em território brasileiro. Erigindo uma paliçada, uma zona de limpeza étnica, uma versão fascista-arianizante do "Branco sobre o Branco", Wim Beeren, querendo botar os negros no tronco do pelourinho, dedo em riste no nariz do mais que doce Paulo Roberto Santana:

- Get out! Get out! Get out ${ }^{\beta 1}$

Propor um modelo filosófico para a autoria artística que desvie do modelo europeu artista-gênio-individual não resolve o racismo e o colonialismo, que são igualmente modelos europeus. Mas ajuda a desestabilizá-los. Práticas e pensamentos simpoiéticos - como os sugeridos por Haraway, mas também como os que são praticados há milênios por povos não ocidentais - são estratégias, entre muitas outras, que estremecem as hierarquias coloniais. Portanto, atuam na construção imaginário-corporal-conceitual de formas viáveis de coexistência nesse mundo danificado.

XXII

Da adversidade vivemos

Estou possuído

Incorporo a revolta

\section{Referências bibliográficas}

ALVES, Marco Antônio Sousa. "Criação e autoria: Considerações sobre as práticas artísticas e intelectuais modernas". Scriptorium, v. 2, n. 2 (dezembro 2016), p. 119-135.

ANZALDÚA, Gloria. Borderlands: The New Mestiza - La Frontera. Tradução própria. San Francisco: Aunt Lute, 1987. 
CABOCO, Gustavo. "O ser humano se reconhece como ser humano?". In: Véxoa: Nós sabemos. São Paulo: Pinacoteca do Estado, 2020.

DUARTE, Rodrigo. "Sobre pós-história e Ciborgues (com um vislumbre da 'estetosfera')". Viso: Cadernos de estética aplicada, v. 12, n. 23 (jul-dez/2018), p. 305-313.

FAVARETTO, Celso. "O grande mundo da invenção". ARS, v. 15, n. 30 (2017), p. 33-47.

FEDERICI, Silvia. Calibã e a bruxa. São Paulo: Elefante, 2019.

FIGUEIREDO Luciano. "Flores da amizade". In: SALOMÃO, Waly. Hélio Oiticica: Qual é o parangolé? Rio de Janeiro: Companhia das letras, 2015.

FREITAS, Artur. Festa no vazio: Performance e contracultura nos encontros de arte moderna. São Paulo: Intermeios, 2017.

HARAWAY, Donna. Staying with the Trouble: Making Kin in the Chthulucene. Tradução própria. Durham and London: Duke University Press, 2016.

KRISTELLER, P.O. "The Modern System of the Arts: A Study in the History of Aesthetics. Part I". Journal of the History of Ideas, v. 12, n. 4 (Oct 1951), p. 496-527.

MOMBAÇA, Jota. $\tilde{N}$ vão nos matar agora. Rio de Janeiro: Cobogó, 2021.

NOCHLIN, Linda. Por que não houve grandes mulheres artistas? São Paulo: Edições Aurora, 2016.

OITICICA, Hélio. "A última entrevista de Hélio Oiticica. Entrevista com Jorge Guinle Filho". In: OITICICA, César; VIEIRA, Ingrid (orgs). Encontros: Hélio Oiticica. Rio de Janeiro: Beco do Azougue, 2009.

Aspiro ao grande labirinto. Rio de Janeiro: Rocco,1986. 
PAZETTO, Debora. "Intersecções entre arte e tecnologia na póshistória: Uma aproximação entre Vilém Flusser e Donna Haraway". Viso: Cadernos de estética aplicada, v. 12, n. 23 (juldez/2018), p. 275-291.

"Corpo e descolonização na arte brasileira contemporânea". Artefilosofia, v. 15 (dezembro 2020), p. 120132.

PEDROSA, Mário. "Arte ambiental, arte pós-moderna, Hélio Oiticica”. In: OITICICA, Hélio. Aspiro ao grande labirinto. Rio de Janeiro: Rocco,1986.

SALOMÃO, Waly. Hélio Oiticica: Qual é o parangolé? Rio de Janeiro: Companhia das letras, 2015.

SHINER, Larry, The Invention of Art: A Cultural History. Chicago: University of Chicago Press, 2003.

TERENA, Naine. "Véxoa: Nós sabemos". In: Véxoa: Nós sabemos. São Paulo: Pinacoteca do Estado, 2020.

Debora Pazetto é professora de história e teoria da arte na UDESC.

${ }^{1}$ Canção de Estação Primeira de Mangueira e Marquinho Art'Samba.

${ }^{2}$ Respectivamente: PAZETTO, 2018; DUARTE, 2018; PAZETTO, 2020.

${ }^{3} \mathrm{O}$ historiador da arte Artur Freitas propõe um conceito muito próximo de estetosfera para descrever esses eventos contraculturais dos anos 60 e 70 : forma-festa. Freitas caracteriza a forma-festa como um estado de prazer estético, lúdico e coletivo, que funciona como uma "promessa de felicidade", similar à ideia de estetosfera como promessa de fraternidade que Rodrigo Duarte esboça na tese XI. A ideia de forma-festa refere-se a "situações estéticas abertas, coletivas e compartilhadas, via de regra realizadas no espaço comum da cidade [...] o artista, se ainda existia como tal, atuava mais como um facilitador da criatividade alheia que propriamente como produtor de uma obra" (FREITAS, 2017, p. 81). A definição é muito próxima, porém, o que acho interessante na estetosfera é que se trata de um conceito filosófico, menos indexado historicamente. Portanto, é um conceito fértil para conectar, por exemplo, a produção artística que resistiu à ditadura com as batalhas de rap do viaduto Santa Tereza, com os Porahei Mbarete, com a Charanga Talismã, com as marchas do $8 \mathrm{M}$, e assim por diante.

${ }^{4}$ A lógica de ordenação do tempo e do pensamento também são formas de colonizar nossa experiência corporal. A desorganização da tradicional ordem 
crescente dos números de capítulos tem como referência os trabalhos da artista Jota Mombaça: Preservation as Metamorphosis, 2020 e $\tilde{N}$ vão nos matar agora, 2021.

${ }^{5}$ Todas as citações no parágrafo abaixo encontram-se entre as páginas $71 \mathrm{e}$ 80 em OITICICA, 1986.

${ }^{6}$ OITICICA, 2009.

${ }^{7}$ SALOMÃO, 2015, p. 74; 75.

${ }^{8}$ SALOMÃO, 2015, p. 31; 32.

${ }^{9}$ FAVARETTO, 2017, p. 34

${ }^{10}$ PEDROSA, 1980, p. 11.

${ }^{11}$ FIGUEIREDO, 2015, p. 131.

${ }^{12}$ CABOCO, 2020, p. 154.

${ }^{13}$ CABOCO, 2020, p. 155.

${ }^{14}$ TERENA, 2020, p. 14.

15 TERENA, 2020, p. 12.

${ }^{16}$ SALOMÃO, 2015, p. 45.

17 SALOMÃO, 2015, p. 28.

${ }^{18}$ ANZALDÚA, 1987, p. 68.

${ }^{19}$ NOCHLIN, 2016, p. 7. Nochlin critica essa concepção porque entende que por trás da pergunta "Por que não houve grandes mulheres artistas?" está o mito do Grande Artista. Isto é, se os artistas são vistos como indivíduos geniais descolados de seu contexto de existência, tendo dentro de si todas as condições de seu próprio êxito, "a falta de êxito das mulheres pode ser formulada como silogismo: se as mulheres possuíssem talento para arte este se revelaria espontaneamente. Mas este talento nunca se revelou. Portanto, chegamos à conclusão de que as mulheres não possuem talento para a arte" (p. 19). Aqui, minha referência a Nochlin tem um objetivo relativamente deslocado: meu foco não está na ausência das mulheres artistas, mas na ausência de outras formas de produção criativa que perderam ou não chegaram a ter o estatuto de arte. Contudo, é evidente que isso não se descola das questões de gênero-raça-classe (para resumir), já que a formulação do mito artista-gênio-individual atende muito bem às demandas do colonizador masculino-branco-burguês.

${ }^{20}$ SHINER, 2003; KRISTELLER, 1951.

${ }^{21}$ ALVES, 2016, p. 127.

22 FEDERICI, 2019.

${ }^{23}$ ALVES, 2016, p. 127.

${ }^{24}$ ALVES, 2016, p. 128.

${ }^{25}$ HARAWAY, 2016, p. 58.

${ }^{26}$ HARAWAY, 2016, p. 67. 
${ }^{27}$ HARAWAY, 2016, p. 61.

${ }^{28}$ HARAWAY, 2016, p. 60.

${ }^{29}$ HARAWAY, 2016, p. 12.

30 SALOMÃO, 2015, p. 49.

${ }^{31}$ SALOMÃO, 2015, p. 55; 56. 